\title{
FATIGUE LIFE PREDICTION FOR PERFORATED PLATE BASED ON INELASTIC BEHAVIOR
}

\author{
KORAKOD PANGLILAD ${ }^{1} \&$ BOPIT BUBPHACHOT ${ }^{2 *}$ \\ ${ }^{1}$ Engineering, Division of Building and Grounds, Office of the President, Mahasarakham University, \\ Maha Sarakham, Thailand
}

${ }^{2}$ Associate Professor, Heat-Pipe and Thermal Tools Design Research Unit (HTDR), Department of Mechanical Engineering, Faculty of Engineering, Mahasarakham University, Maha Sarakham, Thailand

\section{ABSTRACT}

This research aims to present the fatigue life prediction for the perforated plate based on the inelastic behavior of the Neuber's law and the Stress Redistribution Locus (SRL) method. The specimens are made from stainless steel (AISI 304). The temperature is kept to be $550^{\circ} \mathrm{C}$. The geometries of specimens are changed by the diameter size of holes. The Neuber's law and the SRL method are used to predict the cycle number of crack initiation $\left(N_{c}\right)$ and the cycle number to failure $\left(N_{f}\right)$ for the perforated plate. The results demonstrated the prediction method for strain amplitude is employed by the proposed method of the Neuber's law and the SRL method under the strain range of 0.25 and $0.5 \%$. The prediction trend by the SRL method is more accurate for predicting the crack initiation of the perforated plate than that the Neuber's law. However, the selection of accurate and appropriate methods for prediction is the benefit in cost reduction for used material in design and construction.

KEYWORDS: Fatigue testing, Neuber's law, SRL method, Elevated temperature, Perforated plate

Received: Nov 02, 2020; Accepted: Nov 22, 2020; Published: Dec 05, 2020; Paper Id.: IJMPERDDEC202011

\section{INTRODUCTION}

The power systems of nuclear play an important role in energy systems. The new nuclear power system, such as the fast breeder reactor, is designed to operate at an elevated temperature. In the design code, fatigue life is predicted as a significant failure factor. An accurate evaluation scheme is required for the components of stress concentration in order to predict fatigue life $[1,2,3]$. For this purpose of evaluation of inelastic behavior, the American Society of Mechanical Engineers [1] used the simplified methods of Neuber's law [4] for calculating the strain range, or the Japanese FBR design code [3] used Neuber's law and elastic follow-up method. The design factors usually include the margin conservative for the considered geometries and loadings. On the other hand, the inelastic finite element method (FEM) analysis can be applied to estimate the inelastic behavior. It is known that the used constitutive model importantly affects the prediction. Therefore, the finite element method and the simplified method are recommended to apply for an elastic solution and an inelastic strain behavior respectively in the current design codes.

This research is to present the fatigue life prediction for the perforated plate at elevated temperature based on the inelastic behavior of both methods as Neuber's law and Stress Redistribution Locus (SRL) method. The perforated plate made of the austenite AISI304 stainless steel is taken as an example and the elevated temperature is taken at $550^{\circ} \mathrm{C}$. The experimental method employed in the present study is following the report by Watanabe and et al. [5]. In the present study, the applied strain is confined to the small considering the actual condition and the geometry is changed systematically to investigate the capability of the simplified method. The inelastic behavior is estimated by 
Neuber's law and the SRL method as in the study of Watanabe and Koike, 2006. The mechanism of crack initiation and propagation are recorded by the CCD camera by Papirno and et al. [6].

\section{MATERIAL AND METHODS}

\subsection{Specimen}

The stainless steel (AISI 304) was used in this research, where the chemical compositions of AISI 304 are shown in Table 1 and the geometry of the test specimens is shown in Figure 1. The chemical compositions are almost the same value as chemical elements (the spectrometer test). The test specimen is rectangular flange-type. One circular hole is manufactured by a CNC milling machine with the diameters of 4, 6 and $8 \mathrm{~mm}$, respectively as shown in Figure 1.

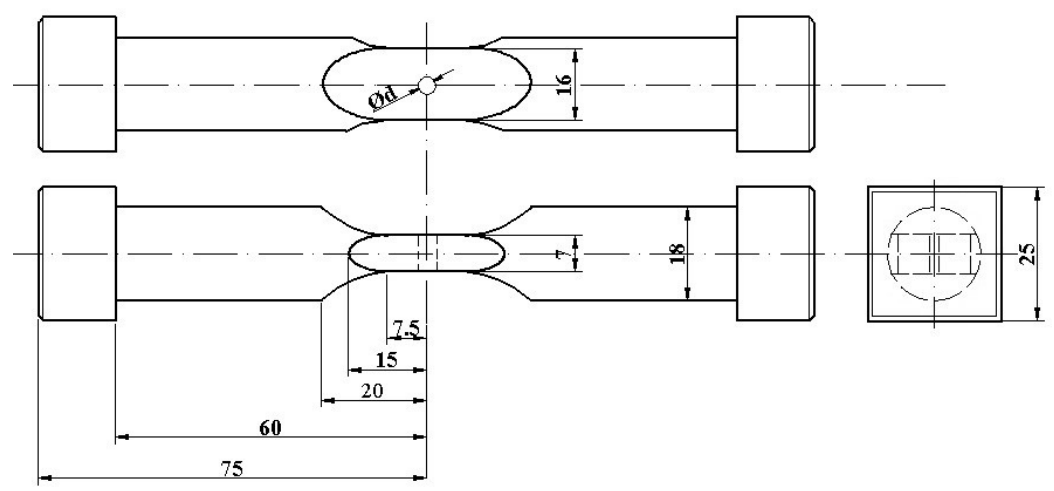

Figure1: Test specimens (unit: mm)

Table 1: Chemical composition (wt.\%) of AISI 304

\begin{tabular}{|c|c|c|c|c|c|c|c|}
\hline $\mathbf{C}$ & Si & Mn & P & S & Ni & Cr & Fe \\
\hline 0.052 & 0.040 & 1.65 & 0.035 & 0.025 & 8.21 & 18.65 & Bal. \\
\hline
\end{tabular}

The triangle ware for loading history is shown in Figure 2. It is applied to the specimen under stain rangecontrolled condition with a strain range ratio of -1 at $550^{\circ} \mathrm{C}$, by using an electro-hydraulic fatigue testing machine. The fatigue test under strain range of 0.25 and $0.5 \%$ are also carried out under the condition at $550^{\circ} \mathrm{C}$ using the electric furnace. The cycle number of crack initiation $\mathrm{N}_{\mathrm{c}}$ is determined from the CCD camera recorder. The failure cycle number $\mathrm{N}_{\mathrm{f}}$ is defined by the number when the tensile load $\mathrm{L}_{\text {peak }}$ is decreased and reached to $75 \%$ of the maximum peak load $\mathrm{L}_{\text {max }}$. At this condition, the testing machine stops. Photographs are taken at the center surface to observe the small crack which is appeared and gradually extended. The cycle number of crack initiation $\mathrm{N}_{\mathrm{c}}$ is determined by the CCD camera recorder [6].

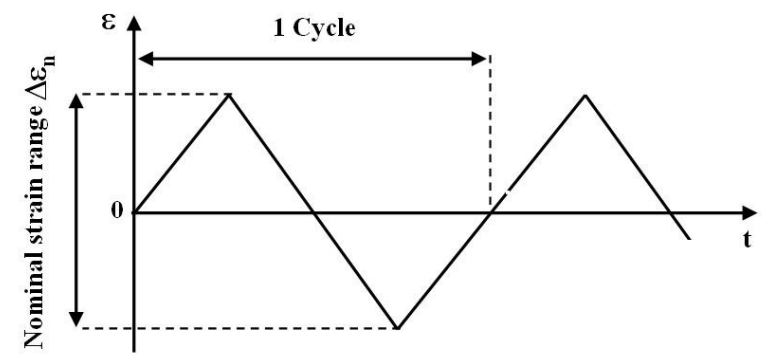


Figure 2: Assumed load wave in the triangle shape

\section{RESULTS AND DISCUSSIONS}

\subsection{Fatigue test}

Table 2 shows the summary of fatigue test with respect to the nominal strain rage, strain concentration factor $\mathrm{K}_{\mathrm{t}}$, Crack initiation cycle, $\mathrm{N}_{\mathrm{c}}$ and Failure cycle, $\mathrm{N}_{\mathrm{f}}$. Figure 3 shows the nominal strain range by number of failure cycle $\mathrm{N}_{\mathrm{f}}$. The agreement with the Best Fit Fatigue (BFF) curve is not good by the two reasons which are related the research of Watanabe and et al. [7] as: 1) The strain becomes large in the hole side and 2) The number of cycles is estimated by the failure cycle, $\mathrm{N}_{\mathrm{f}}$.

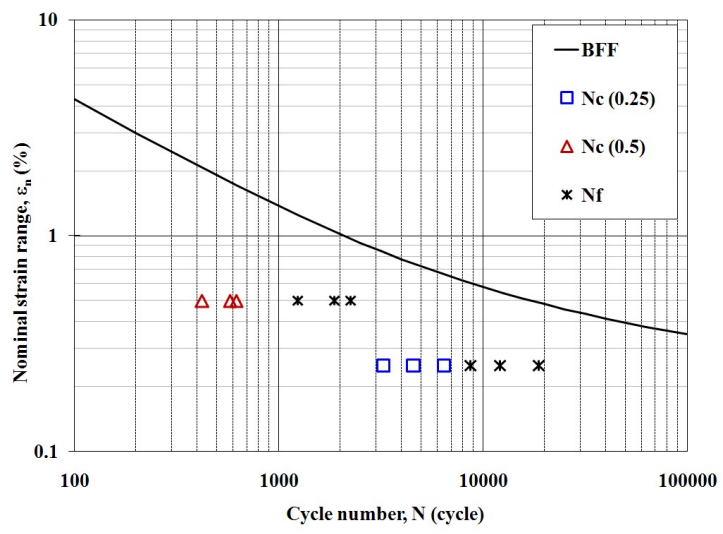

Figure 3: Experimental results of fatigue test

Table 2: Summary of the fatigue test

\begin{tabular}{|c|c|c|c|c|}
\hline $\begin{array}{c}\text { Diameters of hole } \\
(\mathrm{mm})\end{array}$ & $\begin{array}{c}\text { Nominal strain range } \\
(\%)\end{array}$ & $\begin{array}{c}\text { Stress concentration } \\
\text { factor, } K_{t}\end{array}$ & $\begin{array}{l}\text { Crack initiation } \\
\text { cycle, } \mathrm{N}_{\mathrm{c}}\end{array}$ & $\begin{array}{c}\text { Failure cycle, } \\
\mathbf{N}_{\mathbf{f}}\end{array}$ \\
\hline \multirow{2}{*}{ 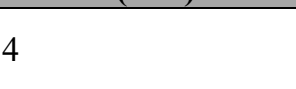 } & 0.25 & \multirow{2}{*}{ 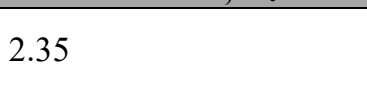 } & 3,260 & 8,715 \\
\hline & 0.5 & & 425 & 1,245 \\
\hline \multirow{2}{*}{6} & 0.25 & \multirow{2}{*}{2.21} & 4,580 & 12,125 \\
\hline & 0.5 & & 578 & 1,875 \\
\hline \multirow{2}{*}{8} & 0.25 & \multirow{2}{*}{2.08} & 6,475 & 18,790 \\
\hline & 0.5 & & 621 & 2,256 \\
\hline
\end{tabular}

\subsection{Crack Initiation}

Figure 4 shows the corresponding photographs to observe the crack initiation. Photographs are taken at the center surface to observe the small crack which is appeared and gradually extended. The cycle number of crack initiation $\mathrm{N}_{\mathrm{c}}$ is presented by Papirno and et al. [6]. 


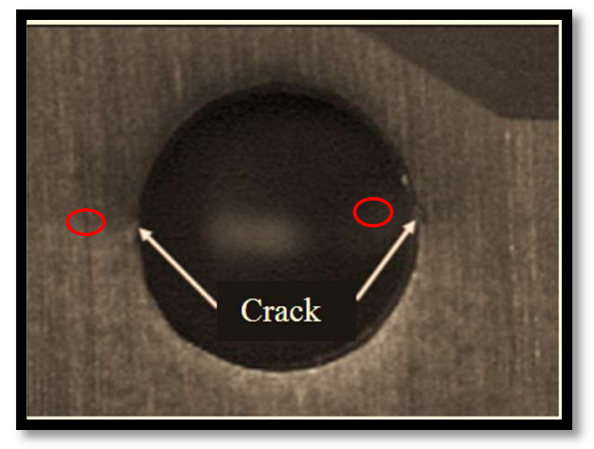

(a) $425^{\text {th }}$ cycle

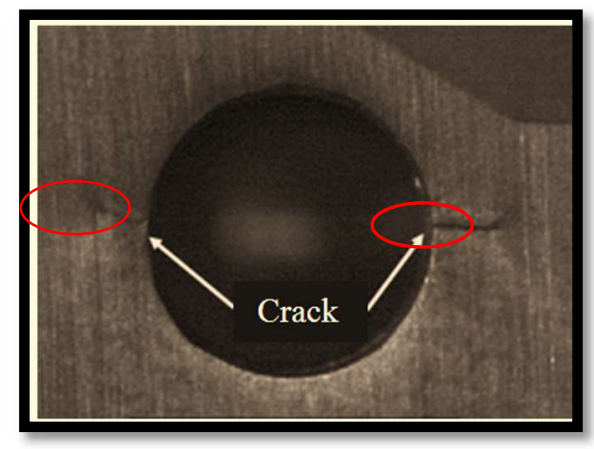

(b) $885^{\text {th }}$ cycle

Figure 4: Crack of test specimen for $\varnothing 4 \mathrm{~mm}$ at $\varepsilon_{\mathrm{n}}$ as $0.5 \%$

\subsection{Stress concentration Factor, $K_{t}$}

Figure 5 shown the 3-dimensional finite element analysis is carried out. The 8-node Isoparametric 3D-element with selective integration technique is used in the elastic analysis which is presented by the Solidwork Program version 2018. The $\mathrm{K}_{\mathrm{t}}$ result as shown in Table 2 .

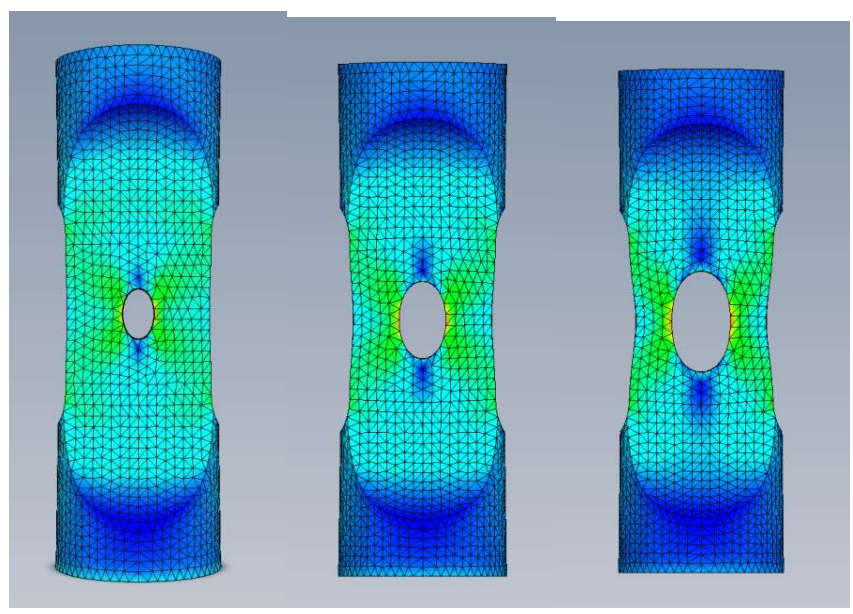
(a) $\varnothing=4 \mathrm{~mm}$
(b) $\varnothing=6 \mathrm{~mm}$
(c) $\varnothing=8 \mathrm{~mm}$

Figure 5: Determination of stress concentration factor $\left(K_{t}\right)$ by the FEA

\subsection{Determination of Stress and Strain}

The simplified methods, such as the Neuber's law is used to estimate the stress or strain concentration. The Neuber's law shows that once the elastic stress and strain $\left(\sigma^{e}, \varepsilon^{e}\right)$ is obtained, then stress and strain $(\sigma, \varepsilon)$ in inelastic region changes so as to keep product of stress and strain to be constant in the inelastic region by Watanabe and et al. [5] as:

$\sigma \varepsilon=\sigma^{e} \varepsilon^{e}=K_{t}^{2} \sigma_{n} \varepsilon_{n}=$ const. (The Neuber's law)

The local stress and strain amplitude in the high stress region are obtained by the intersection point between the Neuber curve and cyclic material stress-strain relation for fatigue strength estimation. As the simplified method to predict the inelastic behavior by the Neuber's law is lower than the experimental results. To solve this problem, the SRL method has been recently proposed and investigated in conjunction with the evaluation scheme of creep-fatigue strength and the 
SRL method approach has the similar form of stress-strain relation as the Neuber's law by introducing the reduction coefficient $\mathrm{k}$ expressed [5] as:

$$
\sigma\left(\frac{\sigma}{\mathrm{E}}+k \varepsilon_{p}\right)=\sigma^{e} \varepsilon^{e}=K_{t}^{2} \sigma_{n} \varepsilon_{n}=\text { const. } \quad \text { (The SRL Method) }
$$

where the reduction coefficient $\mathrm{k}$ is taken as 1.6 from the case study analysis for the Light Water Reactor, LWR components $[3,5]$. The stress and strain can be calculated as the intersection point of the SRL curve and stress-strain curve as shown in Figure 6 and the strain prediction is smaller than the Neuber's law.

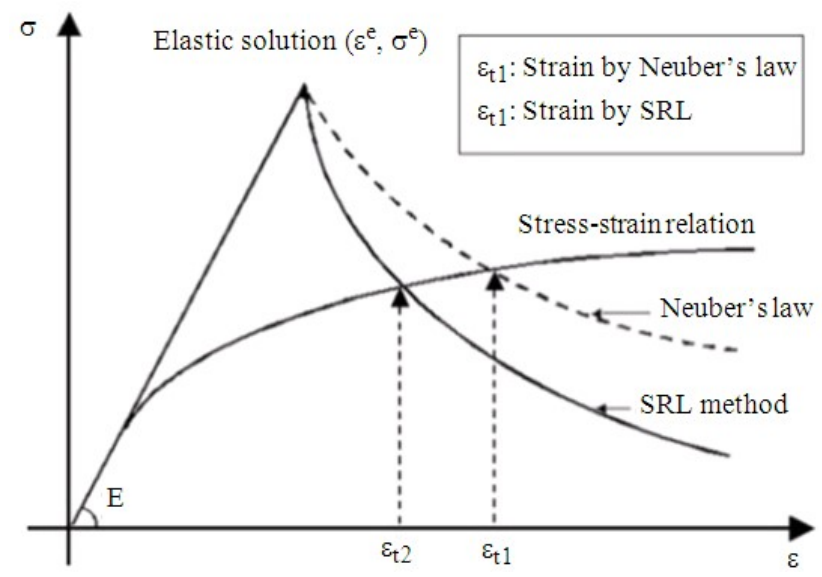

Figure 6: Inelastic strain by the Neuber's law and the SRL method [5]

Figure 7 show the inelastic strain amplitude estimated from the Neuber's law of Equation (1) and Figure 8 and 9 show the inelastic strain amplitude estimated from the SRL method of Equation (2) as a function of failure cycle $\mathrm{N}_{\mathrm{f}}$ and crack initiation cycle $\mathrm{N}_{\mathrm{c}}$, where the inelastic strain amplitude near the hole side can be predicted. The reduction factors $\mathrm{k}$ [5] are taken as 1.0 (the Neuber's law), 1.4 and 1.6 (the SRL method). The results for the reduction factor of $\mathrm{k}=1.6$ are within the factor of 1.5 for all the experimental results, while the results of $\mathrm{k}=1.0$ tends to differ from the BFF curve, even though they are without the factor of 1.5

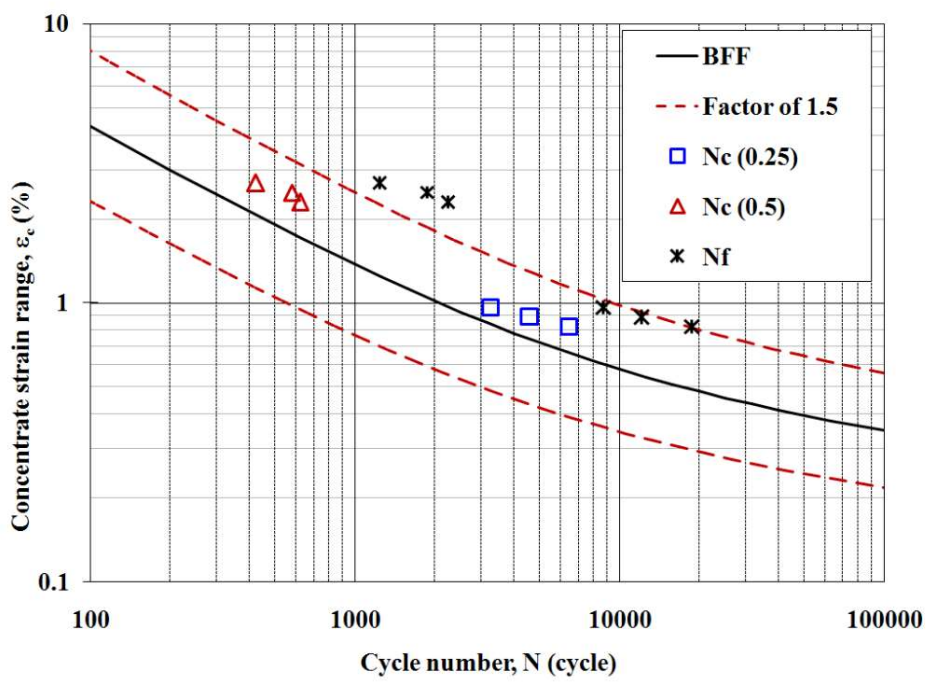

Figure 7: Fatigue test of strain and failure cycle relation by the Neuber's law (the SRL method $(k=1.0))$ 


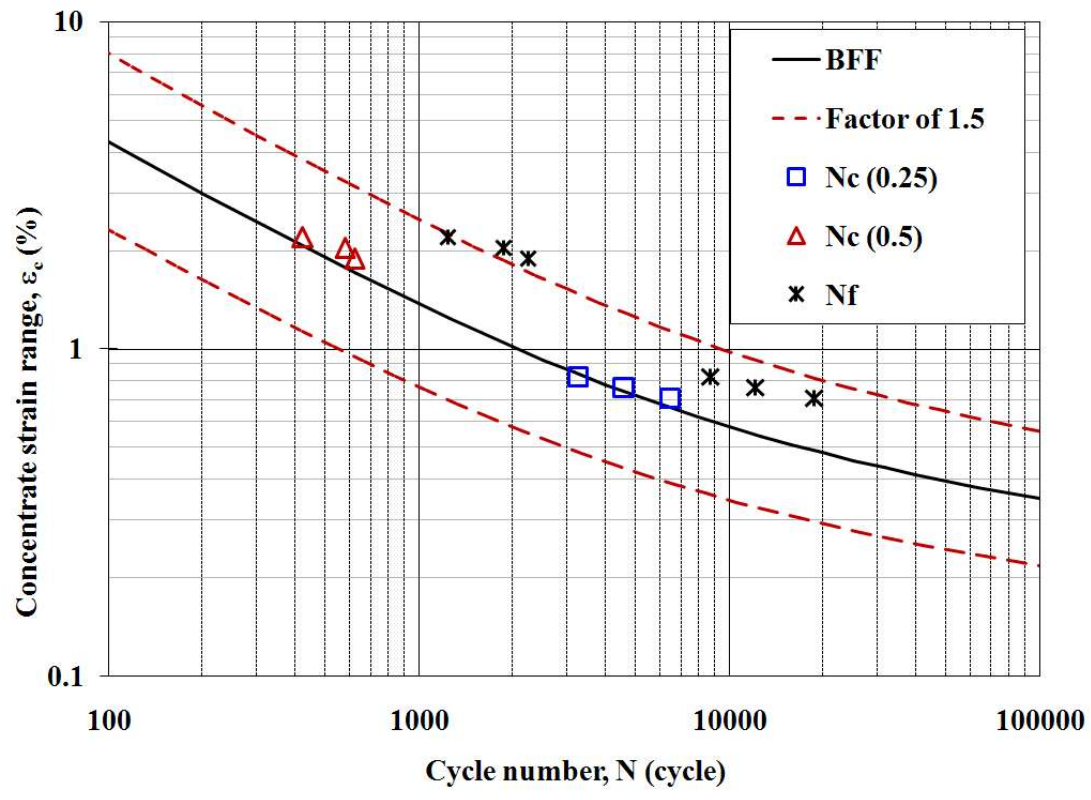

Figure 8: Fatigue test of strain and failure cycle relation by the SRL method $(k=1.4)$

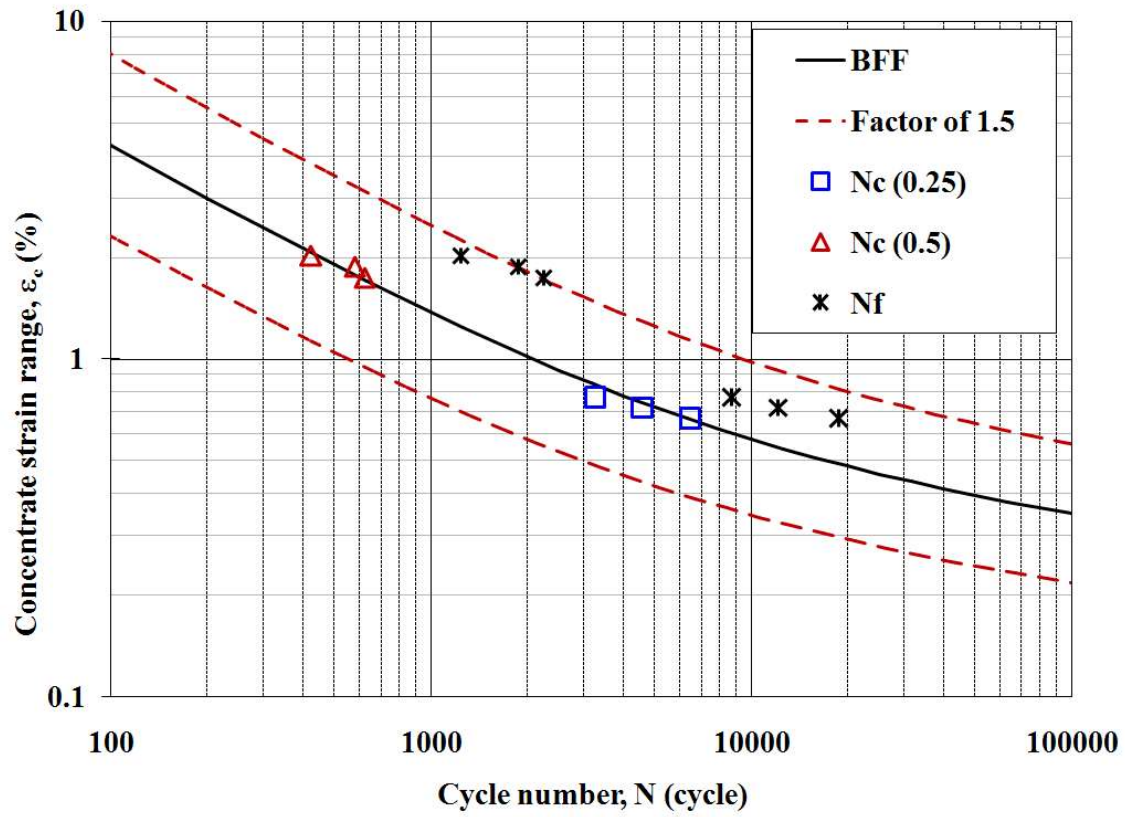

Figure 9: Fatigue test of strain and failure cycle relation by the SRL method $(k=1.6)$

\section{CONCLUSIONS}

The prediction method for strain amplitude is employed by the proposed method of Neuber's law and the SRL method and the results are compared with the experimental one. We conclude the following: 1) The prediction trend by the SRL method is more accurate for prediction the crack initiation cycle of perforate plate than that Neuber's law, 2) Safety factor obtained from the design by Neuber's law is higher than that SRL method and 3) The selection of accurate and appropriate method for prediction is benefit in cost reduction for used material in design and construction. 


\section{ACKNOWLEDGEMENT}

This research was financially support by Mahasarakham University grant year 2012. The authors would like to thank you for the equipment and tools support from the Heat-Pipe and Thermal Tools Design Research Unit (HTDR), Faculty of Engineering, Mahasarakham University, Maha Sarakham, Thailand.

\section{REFERENCES}

1. K. R. Rao, Boiler and Pressure Vessel Code Volume 1, American Society of Mechanical Engineers, 2002 ISBN: 0-7918-0173x, pp. 369-402.

2. High Pressure Institute of Japan, "Creep-fatigue life evaluation scheme for ferritic component at elevated temperature". HPIS. C. 107 TR 2005 (in Japanese).

3. Japan Society of Mechanical Engineers, "Rules on design and construction for nuclear power plants. Division 2: Fast Breeder Reactor", 2005 (in Japanese).

4. H. Neuber, "Theory of stress concentration for shear strained prismatic bodies with arbitrary nonlinear stress-strain law". Trans. ASME. J. Applied Mech., vol. 28, 1961, pp. 544-550.

5. O. Watanabe and T. Koike, "Creep-fatigue life evaluation method for perforated plate at elevated temperature". J. Pressure Vessel Technol. vol. 128, February 2006, pp. 17-24.

6. R. Papirno and B. S. Parker, "An automatic flash photomicrographic system for fatigue crack initiation studies". ASTM STP vol. 519, May 1973, ISSN: 066-0558, pp. 98-108.

7. O. Watanabe, B. Bubphachot, N. Kawasaki and N. Kasahara, 2007, "Fatigue Strength Evaluation of Perforated Plate at Elevated Temperature Using Stress Redistribution Locus Method", Proceedings of the ASME Pressure Vessels and Piping Conference, Vol.9, 8thInternational Conference on Creep and Fatigue at Elevated Temperatures CREEP8, (Principal Editor: Carl), July 22 - 26, 2007, San Antonio, Texas, America, pp. $323-331$.

8. Bopit Bubphachot, Osamu Watanabe, Nobuchika Kawasaki and Naoto Kasahara, 2011. "Crack Initiation Process for Semicircular Notched Plate in Fatigue Test at Elevated Temperature”. Journal of Pressure Vessel Technology. 133 (3): 031403-1-031403-8.

9. Osamu Watanabe, Bopit Bubphachot, Akihiro Matsuda and Taisuke Akiyama, 2012. "Stress and Strain Locus of Perforated Plate Inelastic Deformation: Strain-Controlled Loading Case”. Journal of Pressure Vessel Technology. 134 (3): 031207-1 031207-13.

\section{AUTHOR PROFILE}

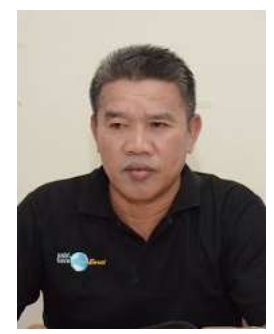

Mr. Korakod Panglilad received his B.Eng. degree in Practice Engineering from Mahasarakham University, Thailand, in 2020. He is currently a Head of Maintenance Group at Division of Building and Grounds, Office of the President, Mahasarakham University, Maha Sarakham, Thailand. His's research interests include Metal Forming, FEM Simulation in 
Metal Forming Process.

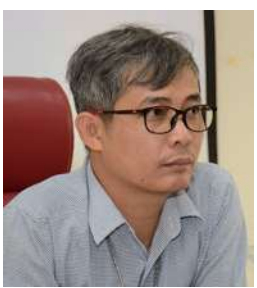

Mr. Bopit Bubphachot received his Ph.D. degree in Engineering Mechanics and Energy from the University of Tsukuba, Japan, in 2008. He is currently an Associate Professor at the Faculty of Engineering at Mahasarakham University in Thailand. His's research interests include Metal Forming (Fine Blanking Process), FEM Simulation in Metal Forming Process, Fatigue and Creep-Fatigue strength for Perforated Plate, Heat pipe, and Heat exchanger. 